\title{
Bionomics of Geohelminth Nematodes in Contaminated Foci in Parts of Abua Communities, Niger Delta, Nigeria (A)
}

\author{
${ }^{1 *}$ AMADI, E C; ${ }^{2}$ UTTAH E. C \\ ${ }^{1}$ Faculty of Science, Department of Applied and Environmental Biology (Parasitology Unit), Rivers State University of Science and \\ Technology, P. M. B 5080, Nkpolu, Port Harcourt, Nigeria \\ *E-mail: amadichiec@yahoo.com \\ ${ }^{2}$ Faculty of Science, Department of Biological Sciences, Cross- River State University of Technology, Calabar, Nigeria
}

\begin{abstract}
A combined field and laboratory investigation was conducted on the bionomics of geohelminths in contaminated foci in Abua communities using the Cobb's decanting and sieving method. The result of the study showed that eggs of Ascaris lumbricoides were 262 (44\%), hookworm, 173 (29\%) and Trichuris trichiura, 102 (17\%). The larvae of hookworm recovered were 323(54\%) and no larvae of Ascaris and Trichuris were recovered. Combination of eggs and larvae recovered from the study, showed that hookworm larvae were 496 (83\%), Ascaris eggs, $317(53 \%)$, and Trichuris eggs, $102(17 \%)$. It was observed that hookworm eggs and larvae were the most abundant, followed by Ascaris eggs and Trichuris eggs. The result of the study was statistically significant at $0.05 \%$ level (f-test $=6.957, \mathrm{p}>0.05$ ). The above indicates that the occurrence of these geohelminths was dependent on the contaminated foci with human faeces. The implication of this, is that human population in the study area should be discouraged from passing out faeces at common spots, considering the health hazard and other complications arising from geohelminth infections.@JASEM
\end{abstract}

Geohclminths (soil-transmitted helminths) are a group of nematode parasites with an essential phase of their asexual lifecycle in the soil. There is a period of persistence in the soil during which the infective stages are protected and preserved (Beaver, 1974). Geohelminth infections are most prevalent in tropical and sub-tropical regions of the developing world, where adequate water and sanitation are lacking (De Silva et al, 2003). Recent estimates suggest that Ascari lumbricoides infects over one billion people, Trichuris 79 millions and hookworm (Ancylostoma duodenale and Necator americanus), 740 million people (WHO, 2008). Chronic and intense gëohelminth infections can contribute to malnutrition, Iron-deficiency anaemia, morbidity and sometimes, health-comprising nutritional status affecting cognitive process, which include tissuereaction such as granuloma and provoking intestinal obstruction or rectal prolapse (WHO, 2008). Fashuyi, (1983) recorded high rate of helminth infections among people without toilet facilities in Lagos State, Nigeria. No report of geohelminth infections exists in the Niger Delta area of Nigeria, therefore, the present study is aimed at determining the human contact activities with contaminated soils and the relative importance of these foci in the transmission and distribution of geohelminths among the six communities of Abua, Niger Delta, Nigeria.

\section{MATERIALS AND METHODS}

Study area and population: The survey was conducted in six communities of Abua, Niger Delta, Nigeria. Abua is located at $4.45^{\circ}-4.490$ North of the equator and $6.30^{\circ}-6.45^{\circ}$ East of Greenwich and has a mainland that extends from the borders of Orasi river in the East to Sombrero in the west, North and South.
The area is a lowly region with many complicated system of natural water channels which arise from below $45 \mathrm{~m}$ along the eastern boundary to above $48 \mathrm{~m}$ in the northern limit. Apart from the northern boundary, the inhabited Abua area would have been an Island. Based on 2003 census, the area has a population of 134420 people with an area exceeding $320.45 \mathrm{sq} / \mathrm{kg}$, therefore, its population density is 78 per $\mathrm{sq} / \mathrm{km}$. There are many creeks and ox-bow lakes which find its way into the main rivers. The area has two vegetational belts - mangrove and freshwater swamps in the eastern part of the area. The drainage system is poor due to numerous water channels, particularly during the wet season when many of the creeks and lakes overflow their banks. The rainfall pattern is between $200 \mathrm{~mm}-300 \mathrm{~mm}$. The annual rainfall has its peak in July, a short break occurs and during the month of September, the rain comes again, which finally declines between the months of October and November each year. The average temperature of the area is $29^{\circ} \mathrm{C}$ during the rainy season and $32^{\circ} \mathrm{C}$ in the months of dry season (December-April). Many economic trees are found in the forest which includes - mahogany, iroko, raffia and oil palms etc. The main occupation of the area is farming at subsistence level, fishing and trading.

Ethical Clearance for the Study: Consent was obtained from the community heads to conduct the study after a bottle of wine was presented as custom demands. During routine visits to the community heads, the relevance of the study was explained. The community heads further assembled their subjects and explained same to them. It is regrettable that some villagers were angry, alleging that the soil samples were used for rituals. Surprisingly, one woman opted to tell her husband who later came to 
the site and the purpose of the study was explained and that the study was permitted by the community heads. The uncompromising attitude of the villagers despite obtaining consent from their village heads, affected immensely the collection of samples for the study.

Physical examination and measurement of soil temperatures of contaminated foci: All the contaminated soils have manure and rich in nutrient. The temperature of the soils when tested was averagely $28^{\circ} \mathrm{C}$ at Owerewere, Aminigboko $24^{\circ} \mathrm{C}$, while Egunighan, Emesu, Obrany, Okoboh have soil temperatures ranging between $21^{0} \mathrm{C}-22^{\circ} \mathrm{C}$.

Collection of soils from contaminated foci: In the six villages studied, there are communal defaecation spots where male and female inhabitants pass out faeces. The six villages are Owerewere, Aminigboko, Egunighan, Emesu, Obrany and Okoboh. These sites were kept for the purpose of defecation and it has been used for many years without changing the sites. The sites have coconut trees, plantains, wild palms, wild cocoyams, oranges and paw-paw. These plants form canopy, leading to humid environment which prevents sunlight from reaching the ground floor of the soils. ample collection started in the morning from 6.00 am -12 noon, when the larvae and eggs of geohelminths are still active and fresh. A quadrat was thrown at random on the defaecation sites and shovel was used to collect $15 \mathrm{~cm}$ topsoil from each quadrat area and the samples collected were kept in black polythene bag and taken back to the laboratory. The random collection of contaminated soils occurred at five different sites in the communities.

Preservation of eggs and larvae in contaminated soil samples: After the collection of contaminated soils, it was taken to the laboratory where $50 \mathrm{gm}$ of each soil sample was measured out into a transparent white plastic plate and $10 \%$ formalin was added to preserve the eggs and larvae of geohelminths.

Examination of contaminated soil samples for eggs and larvae of geohelminths: The method adopted in the extraction of geohelminth eggs and larvae was Cobb's decanting and sieving method (Cobb's 1920). This method requires three buckets (white plastic bucket preferably) and three series of sieves of $1000 \mu \mathrm{m}, 212 \mu \mathrm{m}$, and $63 \mu \mathrm{m}$. The contaminated soil samples taken to the laboratory were turned into a white plastic bucket and water was added to it, so that it can mix properly when stirred. The mixture was filtered through $1000 \mu \mathrm{m}$ aperture into the second bucket, leaving behind heavy soil particles which settled on the top of $1000 \mu \mathrm{m}$ sieve, while the filtrate was collected in another bucket which in turn was turned into the third bucket through the $212 \mu \mathrm{m}$ sieve. The heavier soils that can not pass through the aperture were taken as residue and were put into a value and eosin was added to stain the soil. The filtrate of the second sieve was turned into the third sieve of $63 \mathrm{pm}$. The filtrate of the last sieve was left overnight, so that the water can settle down until next day, excess water was decanted while the residue was put into a value and preserved overnight after staining with eosin. This was washed again to remove the stains from the soils. The eggs and larvae sorted out were placed into a container where $10 \%$ formalin was added to allow for proper identification. The eggs and larvae recovered were examined using oil immersion.

Identification of eggs and larvae of geohelminths: The eggs and larvae of geohelminths were identified using certain features, (Cheesbrough, 1992). The eggs of $T$. trichiura are barrel-shaped with mucous plug at each pole and measure $50-53 \mu \mathrm{m}$ by $22-23 \mu \mathrm{m}$ in size. The eggs of Ascaris are oval or rounded with warty appearance. Larvae of hookworm are not flattened and eggs posses grey cells or are darkbrown and measure between $50-60 \mu \mathrm{m}$ in size.

Analysis of variance: Computation of analysis of variance (Anova) for the three species of geohelminths recovered from the communities showed, the mean for Ascaris as 52.83, Trichuris, 15.33 and hookworm, 82.67. The t-test analysis showed that calculated $\mathrm{x}=6.957$ which is greater than 3.65 (tabulated) at a $=0.0 .5 \%$ level. This implies that the null's hypothesis should be rejected, therefore, the occurrence of the geoheimniths is dependent on the contaminated foci in the study communities.

\section{RESULTS AND DISCUSSION}

The result of the study has shown that geohelminth eggs and larvae are commonly found in the study sites of Abua communities. In Owerewere, Aminiagboko, Obrany, Ascaris eggs had the highest occurrence in the contaminated foci while hookworm eggs occurred more in Okoboh, with moderate occurrence in all the communities. Trichuris eggs were the least recovered except for Owerewere (table 1). Hookworm larvae ( $J_{3}$ stage) were in abundance while none of Ascaris and Trichuris larvae were recovered (table 2). Also combination of eggs and larvae recovered, hookworm had the greatest occurrence, followed by Ascaris (eggs only) and the least was Trichuris (eggs only), (Table 3). 
Table 1: Eggs of Geohelminths recovered from study communities

\begin{tabular}{|l|l|l|l|}
\hline \multicolumn{4}{|c|}{ Species of Geohelminths } \\
\hline Study area & $\begin{array}{l}\text { A. } \\
\text { Lumbricoides }\end{array}$ & Trichuris & Hookworm \\
\hline Owerewere & 52 & 38 & 22 \\
\hline Aminigboko & 72 & 12 & 23 \\
\hline Emesu & 41 & 12 & 25 \\
\hline Obrany & 50 & 12 & 25 \\
\hline Okoboh & 31 & 12 & 53 \\
\hline Egunighan & 16 & 16 & 25 \\
\hline Total & $262(44 \%)$ & $102(17 \%)$ & $173(29 \%)$ \\
\hline
\end{tabular}

Table 2: Larvae of Geohelmintha recovered from study communities

\begin{tabular}{|l|c|c|l|}
\hline \multicolumn{4}{|c|}{ Species of Geohelminths } \\
\hline Study area & $\begin{array}{l}\text { A. } \\
\text { Lumbricoides }\end{array}$ & Trichuris & Hookworm \\
\hline Owerewere & - & - & 38 \\
\hline Aminigboko & - & - & 29 \\
\hline Emesu & - & - & 24 \\
\hline Obrany & - & - & 42 \\
\hline Okoboh & - & - & 125 \\
\hline Egunighan & - & - & 62 \\
\hline Total & - & - & $323(54 \%)$ \\
\hline
\end{tabular}

Table 3: Combination of eggs and larvae of Geohelminths in the study area

\begin{tabular}{|l|l|l|l|}
\hline \multicolumn{4}{|c|}{ Species of Geohelminths } \\
\hline Study area & $\begin{array}{l}\text { A. } \\
\text { Lumbricoides } \\
(\text { eggs })\end{array}$ & $\begin{array}{l}\text { Trichuris } \\
(\text { eggs })\end{array}$ & $\begin{array}{l}\text { Hookworm } \\
\text { (larvae) }\end{array}$ \\
\hline Owerewere & 72 & 38 & 60 \\
\hline Aminigboko & 76 & 12 & 52 \\
\hline Emesu & 46 & 12 & 49 \\
\hline Obrany & 60 & 12 & 67 \\
\hline Okoboh & 39 & 12 & 178 \\
\hline Egunighan & 24 & 16 & 90 \\
\hline Total & $317(53 \%)$ & $102(17 \%)$ & $496(83 \%)$ \\
\hline
\end{tabular}

Generally, parasitic infections abound in Nigeria not only because of our population still live in high unsanitary surroundings with constant faecal pollution of soil by cultural habits of the inhabitants but also as a consequence of tropical environment for easy parasite growth, spread and transmission. From the study, it is evident that geohelminths like hookworm, Ascaris and Trichuris occur in the contaminated soils. It was observed that a lot of hookworm larvae were recovered in three villages Obrany, Okoboh and Owerewere, while eggs of Ascaris, Trichuris and hookworm were recovered in all the communities.

In each of these villages, the soil ecology was very suitable with a lot of organic matter that ensure the survival of geohelminth eggs and larvae. It is possible that the soil moisture and relative atmospheric humidity provided by canopy of the defaecating area favour the survival of hookworm and it is noted that higher humidity is associated with faster development which is available in the Niger Delta. This agrees with Nwosu and Anya (1980), Udonsi and Atata, (1987). As long as ecological conditions are favourable in the contaminated foci, the larvae of hookworm remain quiescent in the moisture films of contaminated soils until contact with suitable host is made where it penetrate through the skin. It is reported that the larvae may migrate in response to the changing moisture conditions of the soil and exhibit negative geotaxis that tend to bring and align it within $15 \mathrm{~mm}$ of the top surface of faecally polluted soil and even onto surface debris and low-growing vegetation which are common features of the study communities. The larvae of hookworm are capable of vertical migration up and down in the contaminated soil, depending on the moisture suction and temperature. This is consistent with Udonsi et al, (1980, 1981). It has been reported that under favourable ecological conditions, larvae of hookworm can survive for a period of three weeks (21 days) and still remain infective. Since the villagers are constantly having contact with these contaminated sites, this account for the more occurrence of hookworm than other geohelminths likes Ascaris and Trichuris.

Flies that perch on the faecal materials deposited on the contaminated soils help to spread eggs of Ascaris and Trichuris. It is noted that seasonality of factors like rainfall, temperature and humidity are important in the transmission of geohelminths. Although, these factors may be relatively constant under tropical conditions, their effect on the immediate environment of the infective larvae and eggs of geohelminths does affect their population dynamics. This is consistent with Nwosu and Anya, (1980).

It is observed that the villagers use dry leaves from the contaminated sites to clean their anus after defaecation. The eggs and larvae of geohelminths may stick on their fingers which are later ingested while eating with unwashed hands or drinking of water or exposed food contaminated by houseflies and other animals. These factors, accounted for the persistence of geohelminths in the study area.

The absence of Strongyloides can not be accounted for in the study. It is known that the parasite has its ability to remain as a low grade infection in the human population for long periods and may cause overwhelming infections in immunologically compromised individuals which is often fatal. Also, the parasite has been identified as a zoonotic infection with non-human primates and dogs being naturally infected. This is consistent with Eneaya and Njom, (2003).

Environmental interaction and sanitation remain the hallmark of geohelminth control and prevention in endemic communities. Many studies in Nigeria reveal that most geohelminths are acquired in areas designated as infection foci. These are usually the immediate environment around homes, schools, 
playgrounds and other public areas. The presence of economic trees such as plantains, bananas, raffia palms, paw-paw and local pears provide cover for defaecating humans and developing larvae and eggs of geohelminths, therefore, making such environments conducive for the transmission of geoheirniths.

The combination of sanitation technology, community hygiene and education on the biology of geohelminths are necessary as an effective control measure of geohelminths. The government should create programmes that provide drugs for infected individuals and enlighten them on the advantage of periodic deworming. It is believed that heavy infection of geohelminths may directly or indirectly affect economic activities of the study communities.

\section{REFERENCES}

Beaver, P C, (1974):- Recent advances in the knowledge of Soil transmitted helmiths. Tranial Journal Health 4: 20-30.

Cheesbrough, M, (1992):- Medical Laboratory Manual for Tropical Countries. 2nd edition. University Press, Cambridge 200-357

Cobb, N A, (1920):- Estimating the nematode population of the soil. Agric. Téch Bur. P1. Ind. US. Dept. of Agric. No. 1: 19-24.

De Silva, N R, Brooker, S, Hot ez, P, J I Montressor, A, Engels and Savioli L, (2003):- Soil Transmitted helminth infections: Updating the global picture. Trends in parasitol 19:547-551.
Eneanya, C I, and Njom, V S (2003):- Geohelminths contamination of some common fruits and vegetables in Enugu, South-West, Nigeria. Nigeria Journal parasitol 24:123-128

Fashuyi, H I, (1993):- The prevalence of helminth eggs in human faeces deposited on the street of Lagos. West African Medical Journal 1(2): 135137.

Nwosu, A B C, and Anya, A O, (1980):- Seasonality in Hookworm infection in an endemic area of Nigerian and its relationship to rainfall. Tropeumedizin und parasitologie. 31:201-208

Udonsi, J K, and Anya, A O, (1981):- Necator americanus: studies on the bionomics in relation to moisture suction. Nigeria Journal of parasitol 2:4-14.

Udonsi, J K, Nwosu, A B C and Anya, A O, (1980):- Necator americanus: Population structure, distribution and fluctuation in population densities of infective larvae in contaminated farmlands. Zeit parasitenk 63:2559

Udonsi, J K, Atata, G, (1987):- Necator americanus: temperature, $\mathrm{pH}$, light and larval development, longevity and desiccation tolerance. Experimental parasitol. 63:136-142.

W.H.O. (2008):- Public Health Significance of intestinal parasitic infections. Bulletin of W.H.O. 65(5): 575-588. 